\title{
III Colóquio «A Nova Lisboa Medieval»: Gentes, Espaços e Poderes
}

(Lisboa, 20-22 de Novembro de 2013). Organização de Catarina Tente, João Luís Fontes, Luís Filipe Oliveira, Mário Farelo e Miguel Gomes Martins.

Luís Filipe Oliveira e João Luís Inglês Fontes

\section{(2) OpenEdition}

\section{Journals}

\section{Edição electrónica}

URL: http://journals.openedition.org/medievalista/335

DOI: 10.4000/medievalista.335

ISSN: 1646-740X

Editora

Instituto de Estudos Medievais - FCSH-UNL

Refêrencia eletrónica

Luís Filipe Oliveira e João Luís Inglês Fontes, « III Colóquio «A Nova Lisboa Medieval»: Gentes, Espaços e Poderes », Medievalista [Online], 15 | 2014, posto online no dia 01 janeiro 2014, consultado o 15 setembro 2020. URL : http://journals.openedition.org/medievalista/335 
Título: III Colóquio «A Nova Lisboa Medieval»: Gentes, Espaços e Poderes

(Lisboa, 20-22 de Novembro de 2013). Organização de Catarina Tente, João Luís Fontes, Luís Filipe Oliveira, Mário Farelo e Miguel Gomes Martins.

Autor(es): Luís Filipe Oliveira / João Luís Inglês Fontes

Universidade: Universidade do Algarve / Instituto de Estudos Medievais

Faculdade e Departamento / Unidade de Investigação: Faculdade de Ciências Humanas

e Sociais - Departamento de Artes e Humanidades / Instituto de Estudos Medievais

(FCSH-UNL)

Código Postal: 8005-139 FARO / 1069-061 LISBOA

Cidade: Faro / Lisboa

País: Portugal

Contacto: Ifolivei@ualg.pt / joaolfontes@ hotmail.com

Fonte: Medievalista [Em linha]. №15, (Janeiro - Junho 2014). Dir. José Mattoso. Lisboa:

IEM.

Disponível em: http://www2.fcsh.unl.pt/iem/medievalista/

ISSN: $1646-740 \mathrm{X}$

Data do texto: 25 de Novembro de 2013 


\section{Colóquio «A Nova Lisboa Medieval»: Gentes, Espaços e Poderes (Lisboa, 20-22 de Novembro de 2013).}

Organização de Catarina Tente, João Luís Fontes, Luís Filipe Oliveira, Mário Farelo e Miguel Gomes Martins.

Luís Filipe Oliveira, João Luís Inglês Fontes

Nos passados dias 20 a 22 de Novembro de 2013, realizou-se em Lisboa o III Colóquio A Nova Lisboa Medieval. A organização foi do Instituto de Estudos Medievais (IEM), que assim retomou uma iniciativa do seu primeiro Director, o Professor Luís Krus, responsável pela criação e pela dinamização daquela série de colóquios. Os organizadores deste III Colóquio, ora subordinado a um triplo tema - Gentes, Espaços e Poderes -, mantiveram o espírito das edições anteriores, apostando na abertura às especialidades mais diversas e fomentando novas abordagens interdisplinares. Tal como se dizia no texto de apresentação do Colóquio, pretendia-se que dessa conjugação de olhares e de saberes resultasse uma melhor compreensão "das diferentes dimensões de um núcleo urbano muito complexo, que era uma das cidades mais dinâmicas do sudoeste peninsular e que cedo se converteria na própria cabeça do reino português".

A adesão dos investigadores das áreas mais diversas à convocatória para comunicações (call for papers) foi particularmente significativa. Das quarenta e duas propostas recebidas, foram seleccionadas perto de trinta comunicações, distribuídas pelos três 
temas do Colóquio e apresentadas por investigadores nacionais e estrangeiros. A elas, juntaram-se quatro conferências por convite, destinadas a esclarecer aspectos menos conhecidos e a permitir comparações com realidades próximas. A primeira serviu de abertura ao colóquio e tratou os problemas do abastecimento de Lisboa. Foi proferida pela Professora Iria Gonçalves, que recordou, sempre num tom muito coloquial, a multiplicidade dos produtos que acorriam à cidade, as diferentes vias utilizadas (por terra, pelo rio e pela foz) e a centralidade dos espaços da Portagem e da Alfândega situados na Ribeira de Lisboa. Coube a Mathew Davies, da Universidade de Londres, a segunda conferência do programa, na qual caracterizou o lugar de Londres no espaço político e económico do reino inglês. As duas conferências restantes, com que se abriram os trabalhos na tarde do dia 21 e na manhã do dia 22, foram apresentadas pelas equipas de arqueólogos responsáveis pelas intervenções no castelo (Ana Gomes e Alexandra Gaspar) e na Casa dos Bicos (Manuela Leitão e Vítor Filipe), tendo carreado dados importantes e inéditos sobre a ocupação da alcáçova e da zona ribeirinha da cidade.

Talvez por isso, os testemunhos da arqueologia ocuparam um lugar de relevo entre as comunicações apresentadas, facto inédito nesta série de colóquios sobre Lisboa Medieval. Entre elas, cumpre destacar as que lidaram com a ocupação do claustro da Sé (Ana Gomes e Alexandra Gaspar), com uma interessante proposta de recuperação do espaço da mesquita, com os vestígios da Judiaria Pequena (Manuel Fialho e Artur Ferreira), confirmando em parte as propostas de Vieira da Silva, ou aquelas que analisaram os testemunhos da ocupação da cidade nos séculos alto-medievais (Sara Prata e Sílvia Casimiro, Banha da Silva e Adriaan de Man), reveladores dos contactos mantidos com o Norte de África e com Bizâncio.

As comunicações que procuraram esclarecer a história da cidade em época islâmica não foram menos importantes. Incluiu-se aqui um inventário parcial das estruturas de defesa costeira da cidade (Marco Borges), com propostas que necessitam ser discutidas e afinadas, uma tentativa de definir o lugar da cidade no maravilhoso árabe (António Rei) e uma recuperação dos contextos das conquistas de Lisboa e de Santarém (Inês Lourinho). A herança moçárabe de Lisboa também não ficou esquecida, com comunicações que precisararam a época de aculturação daquela comunidade lisboeta (Pedro Picoito), ou que reanalisaram, a partir de dados da musicologia, o ofício da 
trasladação de S. Vicente (Manuel Pedro Ferreira) e que situaram a sua produção no contexto da reforma da cabeceira da Sé promovida por Afonso IV. As obras na Sé de Lisboa foram objecto, de resto, de um trabalho que esclareceu a organização do estaleiro na década de vinte do século XIV (José Augusto Oliveira) e que revelou a importância que nele cabia ao trabalho feminino.

Entre as comunicações apresentadas, apenas três lidaram com realidades dos séculos XII e XIII, quer para caracterizar a implantação das ordens militares no espaço urbano (Luís Filipe Oliveira), quer para definir o papel das casas monásticas na organização e no povoamento do termo (André Leitão), quer, ainda, para evocar a relação desenvolvida entre os canonistas e Lisboa (Maria João Branco), a qual era, por vezes, a sua diocese de origem. Das restantes, muitas foram as que fixaram a atenção em cronologias já de finais da época medieval, fosse para caracterizar os problemas do quotidiano com base na chancelaria de João II (Gracilda Alves) e para evocar o trabalho dos artesãos do couro a partir de regimentos do século XVI (Franklin Pereira), fosse para caracterizar o património dos hospitais medievais na Lisboa de Manuel I (Margarida Leme). Também se podem incluir neste conjunto as comunicações que abordaram os problemas do urbanismo e da arquitectura na cidade, seja para caracterizar as suas regulamentações da actividade construtiva (Sandra Pinto), seja para definir a importância dos edifícios e dos equipamentos do concelho (Carlos Caetano), seja, ainda, para identificar as intervenções feitas na época de Manuel I no Paço dos Estaus (Milton Pacheco).

A dimensão mercantil de Lisboa, que havia sido recordada pela conferência da Professora Iria Gonçalves, foi retomada noutras duas comunicações: uma delas ensaiou uma definição do lugar da cidade nos circuitos comerciais da Europa dos séculos XIV e XV (Flávio Miranda e Diogo Faria), propondo a existência de três fases distintas até que ela se transformasse num entreposto obrigatório para os mercadores europeus; a outra recuperou a figura de João Vasques de Almada, o filho de um mercador de Lisboa que faria carreira em Inglaterra, primeiro como vassalo do rei inglês e depois como embaixador de João I, sem que tivesse abandonado as lides mercantis (Tiago Faria). Por atenção àquela que foi a projecção europeia de um dos seus membros, talvez se pudesse incluir aqui o invulgar estudo da identidade heráldica dos Bulhões (Carlos Carvalho da Fonte), uma das linhagens de Lisboa. 
Os discursos culturais produzidos pelos representantes da cidade, ou pelos diversos grupos que nela residiam, também tiveram um lugar de destaque. Dos primeiros, foi analisada a argumentação evocada pelos delegados enviados por Lisboa às Cortes do século XIV e das primeiras décadas da centúria seguinte (Adelaide Milán Costa), que atesta o crescente protagonismo da cidade na vida do Reino, e, talvez, até a construção de uma identidade própria. No que respeita aos segundos, procedeu-se à recuperação das vivências nas judiarias por finais da Idade Média (José Tavim), à caracterização dos manuscritos hebraicos de Lisboa (Tiago Moita) e à tentativa de precisar a singularidade cultural daqueles códices no contexto peninsular (Luis Urbano Afonso), posto que a sua cronologia sugira uma conexão íntíma com a expulsão dos judeus do reino de Castela.

Após o encerrramento dos trabalhos na tarde do dia 22, os participantes no III Colóquio tiveram a oportunidade de visitar o Castelo de São Jorge e a Casa dos Bicos. A primeira visita foi guiada por Ana Gomes e Alexandra Gaspar, arqueólogas da Direcção Geral do Património Cultural (DGPC), responsáveis pela intervenção arqueológica realizada naquele espaço. A visita à Casa dos Bicos, onde se procederá à musealização dum troço das muralhas da cidade, foi conduzida por Manuela Leitão, arqueóloga da C. M. de Lisboa e coordenadora do projecto de estudo e valorização da Cerca Velha. 


\section{COMO CITAR ESTE ARTIGO}

\section{Referência electrónica:}

OLIVEIRA, Luís Filipe; FONTES, João Luís Inglês - "III Colóquio «A Nova Lisboa Medieval»: Gentes, Espaços e Poderes (Lisboa, 20-22 de Novembro de 2013.

Organização de Catarina Tente, João Luís Fontes, Luís Filipe Oliveira, Mário Farelo e Miguel Gomes Martins.” Medievalista [Em linha]. №15, (Janeiro - Junho 2014).

[Consultado dd.mm.aaaa]. Disponível em

http://www2.fcsh.unl.pt/iem/medievalista/MEDIEVALISTA15/oliveira_fontes1511.html.

ISSN 1646-740X.

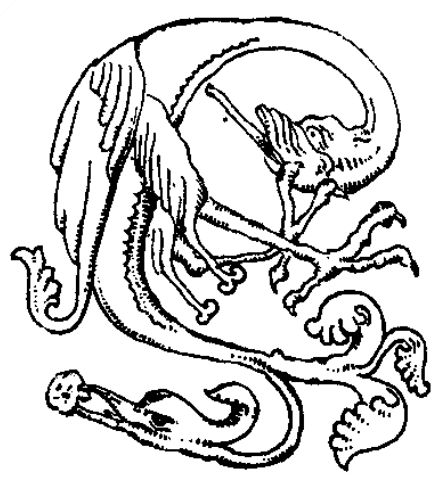

